\title{
Article
}

\section{An analysis of HCPC fitness to practise hearings: Fit to Practise or Fit for Purpose?}

Leigh, J, Worsley, Aidan Richard clive and McLaughlin, K Available at http://clok.uclan.ac.uk/18827/

Leigh, J, Worsley, Aidan Richard clive ORCID: 0000-0002-3925-3297 and McLaughlin, K (2017) An analysis of HCPC fitness to practise hearings: Fit to Practise or Fit for Purpose? Ethics and Social Welfare, 11 (4). pp. 382-396. ISSN 1749-6535

It is advisable to refer to the publisher's version if you intend to cite from the work. http://dx.doi.org/10.1080/17496535.2017.1293119

For more information about UCLan's research in this area go to http://www.uclan.ac.uk/researchgroups/ and search for <name of research Group>.

For information about Research generally at UCLan please go to http://www.uclan.ac.uk/research/

All outputs in CLoK are protected by Intellectual Property Rights law, including Copyright law. Copyright, IPR and Moral Rights for the works on this site are retained by the individual authors and/or other copyright owners. Terms and conditions for use of this material are defined in the policies page.

\section{CLoK}

Central Lancashire online Knowledge www.clok.uclan.ac.uk

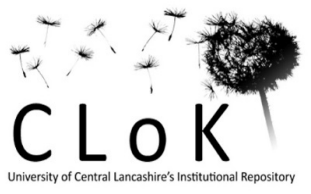


Fit to Practise or Fit for Purpose? An analysis of the Health and Care Professions Council's decision-making process in relation to social workers brought before a 'Fitness to Practise' hearing.

\section{$\underline{\text { Abstract }}$}

All professions regulated by the HCPC have 'protection of title'. This means that only those on its relevant register can legally work as or call themselves a social worker. As such, the HCPC's Fitness to Practise panel wields a lot of power over individuals brought before it, effectively being able to prevent them from gaining employment as a social worker or imposing conditions on their practice. This article reports the findings from a study which examined cases on the HCPC website. The aim was to analyse what happens when an initial investigation finds that there is a case to answer, what factors influence the findings of the Fitness to Practise panel and how the outcome of the hearing then affects the social worker subject to the HCPC process. Using thematic analysis, our findings suggest that the seriousness of the alleged misconduct does not necessarily relate to the severity of sanction applied. It is the social worker's engagement with the process, her insight into the issues and her credibility as a witness that appears to have the most significant bearing on the level of sanction applied.

\section{Introduction}

On August $1^{\text {st }} 2012$ the Health and Care Professions Council (HCPC) assumed responsibility for the regulation of social workers in England, taking over this role from the General Social Care Council (GSCC). Previously known as the Health Professions Council (HPC), the addition of social workers to its regulatory responsibilities led to a change of name from the HPC to the HCPC. Elsewhere we (authors, 2015) have discussed the rise of professional and 
statutory regulation within both health and social work but in this paper we wish to explore the procedural aspects of the HCPC process once a concern is raised. In particular, we will focus on what happens when an initial investigation finds that there is a case to answer, what factors influence the findings of the Fitness to Practise panel and how this affects the social worker subject to the HCPC process.

All professions regulated by the HCPC have 'protection of title' which means that only those on its relevant register can legally work as or call themselves a social worker. As such, the HCPC's Fitness to Practise panel wields a lot of power over individuals brought before it, effectively being able to prevent them from gaining employment as a social worker or imposing conditions on their practice. We acknowledge that there are undoubtedly cases where social workers are so lacking in competence, or are found to have committed serious criminal acts, that they should be prevented from practice. However, it has been argued that some employers appear to be more inclined to formalise concerns via the misconduct process rather than attempting to resolve them themselves (Furness, 2015). This raises an important issue in that some of the referrals made may be related, at least in part, to wider organisational problems rather than the sole failings of a social worker. It is this concern that prompted this part of our research. We were particularly interested in exploring cases where, although there may have been organisational inadequacies, it was an individual social worker who had been referred to the HCPC.

To gain a better understanding of some of these issues we examined cases which were readily available to the public on the $\mathrm{HCPC}$ website. We selected cases where social workers had been brought before a Fitness to Practise hearing, and where a decision had been made 
as to whether the social worker in question had been either 'struck off' the HCPC register, issued with a 'caution', 'conditions of practice' or 'no further action'.

In this paper, we begin by briefly explaining the Fitness to Practise procedure before discussing our method and findings. We conclude by noting that the seriousness of the alleged misconduct does not necessarily relate to the severity of sanction applied. It is the social worker's engagement with the process, her insight into the issues and her credibility as a witness, as judged by the panel members, that appears to have the most significant bearing on the level of sanction applied.

\section{A Case to Answer: The Fitness to Practise Procedure}

The HCPC is the regulator for sixteen professions and is concerned with whether or not individual professionals are 'fit to practise' by which it means they possess 'the skills, knowledge and character to practise their profession safely and effectively' (HCPC, 2012b:1). The inclusion of 'character' indicates that fitness to practise covers more than just professional competence; it also includes 'acts by a registrant which may affect public protection or confidence in the profession'. This may include matters 'not directly related to professional practice' (ibid.). In effect, this extends the scope of the HCPC's remit into the private life of its registrants which has, since the introduction of the social care register with the now disbanded General Social Care Council (GSCC), given rise to the $24 / 7$ social worker: not always on watch but always being watched (Author, 2007).

It is worth noting the scale of the HCPC's endeavour in this area. According to its 2014/15 Fitness to Practise report the number of registrants it is responsible for has nearly doubled in the last five years to just under 331,000 registrants, largely because of the inclusion of social workers. In 2014/15 there were 2,170 cases in total referred to the HCPC for 'Fitness 
to Practise' concerns, of which 1,251 involved social workers, approximately $58 \%$ of the total. Of the 1251, 293 were referred to the HCPC by an employer and 696 were referred by members of the public. Of all the referrals made by the public to the HCPC regarding the professions it regulates, $70 \%$ related to a social worker. This probably reflects the often contentious nature of the social work role in navigating the public/private divide (FoxHarding, 2008). Overall, $1.42 \%$ of registered social workers were the subject of some concerns, more than any other profession. The next highest was paramedics (1.09\%). Social work does, however, have most cases closed at the initial information gathering stage, therefore no further referral is made to the Investigation Committee (614/59\%).

Once an allegation is made and the investigatory process underway, in most cases the individual will remain on the HCPC register, only being removed if the case goes to a hearing and the ruling of the tribunal is that s/he be 'struck off'. However, in certain circumstances, for example if there is a suggestion that the person may pose a risk to themselves or other people, or for other public interest reasons, the HCPC can apply to the Practice Committee Panel for an 'interim order' (HCPC, 2013b). An interim order, if granted, takes effect immediately and would prevent the social worker from practising, or place limits on their practice, until such a time as the case is heard and a final decision made (HCPC, 2012a).

If the investigating panel decides that there is a case to answer the HCPC instigate proceedings for the case to be heard at a formal hearing. Conduct and competence hearings will normally be open to the public and the press, although all or part of a hearing may be held in private in cases where confidential information may be disclosed, or to protect service user anonymity and/or the private life of the registrant or witness. However, panel decisions and the reasons for them must always be given in public. 
The panel considering the case will normally comprise of a registrant from the same profession as the person being investigated. In addition, there will be a lay person who is not registered with the HCPC and a chair (who may be a lay person or a HCPC registrant from any regulated profession, not necessarily the same one as the defendant). The Chair will lead the hearing and speak on behalf of the panel. Also in attendance will be an independent legal assessor/solicitor who will give advice on law and procedure to all those taking part in the hearing, and a transcript writer who will take notes of all that is said at the hearing.

If the panel finds the case is well-founded, there are a range of actions it can make. It can:

caution you (place a warning against your name on the Register for between one to five years); set conditions of practice that you must meet (which might include, for example, insisting that you work under supervision or have more training); suspend you from practising (for no longer than one year); or strike your name from our Register (which means you cannot practise).

(HCPC, 2012a:17).

In determining fitness to practise the HCPC, as did the GSCC before it, uses the civil standard of proof when determining the outcome of its conduct hearings. The decision, therefore, rests on the balance of probabilities rather than the higher criminal proceedings standard of beyond reasonable doubt (HCPC, 2012c). Once a decision is taken and sanction imposed this is not necessarily the end of the process. The Professional Standards Authority for Health and Social Care reviews all final decisions made by the regulators' fitness to practise panels. It has the power to refer those decisions to court if it considers they are unduly lenient and do not protect the public. The social worker has the option to appeal the decision and/or sanction to the High Court but this will come at considerable personal financial expense. 
Given the power of the HCPC and the consequences for social workers subject to its investigatory procedures, analysis of the workings of the hearings and influences on the decisions made, in respect of the sanctions imposed, have obvious relevance for the social work profession. From $1^{\text {st }}$ April 2014 to $31^{\text {st }}$ March 2015155 social workers went before the above committees of which: 23 were struck off the HCPC register; 28 received a caution; 12 had conditions of practice; 4 had no further action; 33 were suspended; 9 cases were discontinued; 36 allegations were judged to be not well founded; 1 was removed from the register for an incorrect/fraudulent application and 9 were removed by consent (HCPC, 2015a).

\section{Method}

The HCPC website has details of all cases that led to a social worker being called before a Fitness to Practise hearing. We looked at all 'final hearings' heard by the HCPC from its inception as the regulatory body for social work on 1st August 2012 through to December 31st 2014. These were cases in which a formal decision had been made as to whether to strike the social worker off the register, subject them to conditions of practice, a caution or no further action.

As mentioned previously, we focused on cases whereby a complaint had been made against the social worker that related to practice issues such as: case management, professionalism and competence. We therefore excluded those cases where the reason for concern over the social worker's fitness to practise was related to issues such as drugs, alcohol, fraud or abuse. The reason for this focus was an attempt to explore the organisational and systemic issues that surround and underpin the HCPC referral and investigatory process. 
Our search of the HCPC website revealed ninety-three cases (66 struck off; 22 cautions or conditions of practice; and 5 that resulted in a finding of no further action). We each looked briefly at the 'Notice of Allegations' made against the 93 social workers and made an individual decision as to whether or not we thought they met the criteria for further analysis. Together we then met to compare our decisions and discuss any anomalies before making a final decision on which cases we would analyse further. This resulted in 34 of the 93 cases being included ( 21 struck off, 6 cautions, 3 conditions of practice and 4 no further actions). The reason why the fifth no further action was not included was due to no details of the case, apart from the registrant's name and hearing outcome, being available on the website for us to explore further.

Ethical approval was obtained initially from the University of $X$ followed by agreement from the other institutions hosting the authors. Although the registrants' full names are provided on the HCPC website, for sensitivity reasons we took the decision not to name social workers. We have used letters from the alphabet in order of the case discussed.

\section{Data analysis}

We split the 34 remaining cases between us by dividing them into three groups of 23 so that each of us looked at 14 'struck off', 6 'cautions' or 'conditions pf practise' and 3 no further action cases. This allowed us to overlap the cases and meant that two people analysed each case. Each case had its own set of minutes which followed the same basic pattern: outline of allegation, summary of findings, decision on facts, grounds, impairment and sanction. The minutes conclude with the 'order' which is the final outcome. In using thematic analysis on this raw data we employed a broad understanding from Braun and Clarke (2006), developed in Author (2011). This familiar approach emphasises the coding and theming of the data 
through thorough reading and examination. This form of thematic analysis allowed us to draw on notions of grounded theory (Corbin and Strauss 2008; Alston and Bowles 2013) especially in relation to going back and forth on issues of codes and themes to best capture meaning. Themes were selected primarily based on recurrence, pattern and relationship (Carey, 2012).

\section{Methodological considerations}

Our research at this stage constitutes an examination and secondary analysis of existing data which Hakim usefully describes as, 'any further analysis of an existing data set which presents interpretations, conclusions or knowledge additional to, or different from those presented in the first report' (Hakim, 1982:1). On a surface level, the use of data from secondary sources presents minimal methodological challenges. However, it is worth noting some of the inherent issues underpinning the use of this data.

Kirk and Miller (1986) talk of 'synchronistic reliability', that is how varying observations are similar over time. This has been an element within the research project as a whole, which took place within an identified time period, and would therefore benefit from the element of triangulation. This will take place in the second phase of this study which involved indepth semi-structured interviews with registrants who had been through the HCPC process and will be documented in the third article of this series.

Similarly, however, we were also presented with challenges around the issue of validity how far our account represents accurately the phenomenon to which we refer (Hammersley 1990). We have been vigilant in qualifying inferences (Silverman 1999: 152) and have heeded Robson's (1998) warning in relation to problems that may accrue when using information collected for one purpose being used for a different one. In this regard, we tried 
to emphasise the extraction of understanding that suggests questions - or patterns - rather than provides direct answers. There is, therefore, an element of 'back to front' design in our methodological approach (Hakim, 1987) where we have designed our approach based on what data we knew was available from the HCPC. We therefore wish to acknowledge the limits of the quality of our data but at the same time attempt to address this issue openly within this context.

\section{Findings}

Before discussing the three themes that emerged it is of interest to explore some of the key characteristics of the cases examined. The minutes of the HCPC hearings, whilst broadly similar in layout are not identical in basic detail, for example, they do not contain any demographic data beyond an inferred gender from the text. On that note, of the 21 registrants struck off, 10 were female and 11 male, a surprisingly marked difference to the broader social work population which tends to be around $80 \%$ female (Skills for Practice, 2016).

With regard to length of service it was possible to estimate length of service in all but 3 of the 34 cases. It was interesting to note, however, that of those struck off in the 18 cases where a reasonable inference could be made, the length of service was an average of $151 / 2$ years. This dropped to just under 10 years for those given conditions or cautions - but rose to $133 / 4$ years for the cases where no further action was taken. So, rather than newly qualified social workers being more likely to be brought before a Fitness to Practise (FTP) hearing the opposite appears to be the case. The reason for this may be because more experienced workers are more resistant to modern workforce practices which are increasingly driven by managerialism, performance indicators and targets (Fox-Harding, 
2008). Such a failure to embrace this new form of social work practice could incur the wrath of more senior staff for whom 'process and compliance, rather than initiative and professional judgement come to the fore' (Rogowski, 2010:143).

'Attendance' and 'Representation' are two aspects of the hearing process that are noted in the minutes and these refer to whether the registrant was there for the proceedings and/or represented by a solicitor or union representative. As we will discuss shortly this was quite significant because none of the 21 'struck off' registrants we looked at either attended or were represented. Therefore, being struck off is something done to social workers indirectly- they simply are not there. However, of those 9 given cautions or conditions, 7 attended the hearing 3 of whom also had representation (by BASW or Unison). Where cases received no further action, all 4 registrants attended and one of those was also represented. The fact that 3 of the no further action did not have representation indicates that it is not essential in order to receive a favourable outcome. However, the importance of representation is confirmed by HCPC statistics in relation to all the professions it regulates (HCPC, 2015a: 36).

It is of interest to note that in relation to areas of professional practice, in the 34 cases we looked at, $63 \%$ of the social workers referred to a Fitness to Practise hearing were from Children and Families teams (this proportion rises to $76 \%$ of the cases eventually struck off). Mental Health was the next highest area (21\%), with Adults (10\%) and Youth Offending (6\%) both relatively less well represented.

\section{Emerging themes}

From the 34 cases that we analysed three distinct themes emerged: 
1. The HCPC panel's opinion as to whether the registrant was a 'credible' or a 'noncredible' witness was a significant factor in its decision on sanction.

2. The outcome of the hearing was not always dependent on the perceived seriousness of the registrant's misconduct or competence.

3. Where organizational issues were identified and were believed to have contributed to the Registrant's poor performance, these were not further explored by the HCPC.

In order to explain how these three themes developed, examples from cases which were issued with either: Struck off; Conditions of practice or Caution; and No further action will now be explored in more detail.

\section{Decision on Sanction: 'Struck off'}

It was immediately apparent that in the 21 cases where registrants were 'struck off', none were present at their hearing. It would appear that their lack of presence was seen by the HCPC panel as evidence that the registrant was not demonstrating full insight into their conduct and were thus inferred to be "non-credible" witnesses. In the notice of allegations, the HCPC has recorded on a number of occasions that the Panel "drew no inference from the absence of the Registrant from the hearing". However, it was not clear how the "burden of proof" could justly be assessed when the Registrant was not there to provide their version of events. Although in some cases registrants provided written submissions, this information was not accessible for us to view on the website.

In the case of ' $A$ ', who was alleged to have not made statutory visits and falsified records, the panel concluded that the Registrant had not demonstrated "full insight" into her failures. In this case the panel drew from the Registrant's written representation because in 
it she apparently acknowledged that her fitness to practise was impaired at the time of "these failures" but did not think she was "currently impaired". As the Registrant was not present and because no information from the Registrant's written representation is produced in the notice, it is difficult to understand how the panel reached the conclusion that she was in "denial" by "downgrading the seriousness and urgency" of the child protection issues.

In some of the cases examined, it could be argued that the perceived "failures" of the Registrant may have emerged as a result of organisational issues. In the notice of ' $B$ ', the panel note that on a number of occasions the Registrant was not provided with regular or "proper supervision" yet this is not considered a concern. Instead, the Panel determined that this Registrant had "displayed a lack of insight into the deficiencies" in spite of inadequate supervision or support from the local authority. The Registrant was not present at the hearing and thus the Panel concluded that there was an "obvious risk of repetition". In the case of ' $C$ ', referred to the HCPC after she was alleged to have not recorded or updated risk plans on the system but misled colleagues into believing she had, the FTP Panel stated that it was apparent that:

...the dishonesty aspects of the Registrant's conduct are not easily remediable. There is no evidence before the Panel to show that the Registrant has insight into her actions....Her dishonesty means that the Registrant's integrity cannot be relied upon.

The decision that the Registrant was dishonest initially emerged from reports that were filed by the local authority and from the witnesses who gave evidence at the hearing. However, the 'dishonesty' label was further developed because there was a lack of interaction with the Registrant. The Panel was not able to find out if the Registrant's conduct was "easily 
remediable" or indeed if her "integrity could be relied upon" because she was not present for them to speak to and neither did she submit a written representation. Whilst it was the Panel's opinion that the Registrant had voluntarily absented herself because she had provided no information to indicate that she would attend, the real reason for her absence was not actually known. What is of interest is that there was evidence in the minutes that ' $C$ ' was receiving ineffective and sporadic supervision. In several of the cases we examined social workers cited this issue as a contributing factor to their alleged impairment alongside illness or organisational bullying.

For example, in the case of ' $D$ ' it was accepted that the Registrant had ill health and was "off sick" intermittently. Whilst the Panel acknowledged that this period of absence from work would not only impact on the Registrant's ability to keep up with her work but also place her under increased pressure, they did not appear to explore what, if any, support mechanisms were implemented to help the Registrant carry out her job effectively. The Panel was satisfied with the evidence given by the line manager that supervision should only have consisted of reminding the Registrant of her duties and asking if she needed training. As the Registrant had 30 years of professional experience, this suggests a very basic understanding of professional social work supervision. As Beddoe (2010) argues, supervision plays a major role in safeguarding social workers because it can support practitioners in managing emotions and uncertainty.

Although the registrants who did not attend were often referred to as "non-credible", what is particularly striking is that in many cases where witnesses gave evidence against the registrant, they were often likely to be referred to as "credible". For example, in the hearing of ' $\mathrm{E}$ ', one of the witnesses was described as "credible, fair and balanced as a witness" 
without any explanation of how this decision was reached. Whilst we recognise that this is not the primary function of the Panel to prove, a little more information was provided in terms of how this decision was reached in the case of ' $F$ '. In this hearing, witnesses were described as "credible" and "candid", with no "particular axe to grind". They were also described as "child centred" and "very concerned", two social work characteristics that in any other situation would be considered difficult to assess without a formal observation of their practice.

Nonetheless what is apparent from all of the cases is that without a registrant being present the HCPC Panel appears to rely on the evidence provided by the witnesses who do attend. It is their presence that provides the 'credibility' that the Panel is looking for when trying to determine the level of seriousness of the allegations that have been made. The written representation supplied by a registrant, although considered by the Panel, does not always appear to be taken seriously. When concerns are raised by a registrant in their written representation about the conduct of the organisation the Panel seem to have in some cases used this as evidence that the Registrant "does not accept the allegations", or "blames everyone and everything without focusing on the allegations". Without being present to refute the allegations made, the inferred lack of insight appears to lead the Panel to the decision that the Registrant is not credible.

\section{Decision on Sanction: 'Conditions of Practice' or 'Caution'}

In contrast to the 'struck off' cases, with the 'Conditions of practice' or 'Caution' cases the majority of registrants did attend the hearing. However, in the cases where they did attend, Registrants were often seen as only being partially credible, being described as having only 
"shown some insight" or a "degree of insight" into the errors of their ways. For example, in the case of ' $G$ ', who was given 'conditions of practice', the Panel found the following:

The Registrant admitted her failings in so far as record keeping was concerned. However, there was little evidence of appropriate reflection, or acceptance that her failure to undertake the required visits and meetings.....gave rise to any risk of harm to the children she was responsible for.

From the cases we analysed it appeared that the seriousness of the allegations made against Registrants who received 'conditions of practice' or 'caution' were no less severe than for those Registrants who had been struck off. In fact, in some cases they appeared to be more serious. For example, with the case of ' $\mathrm{H}$ ' the allegations spanned three pages and included poor communication, insufficient record and time keeping, not meeting service users and making inappropriate comments. However, because the Registrant attended his hearing and was able to show "some insight" into his "failings" by expressing his "genuine regret" for them, it was felt by the Panel that his fitness to practise was not currently impaired and he was thus given a caution.

It is of interest to note that there was one case, ' $I$ ', where the Registrant did not attend but still only received a caution. The Panel were aware in advance that the Registrant would not be present as she sent a letter stating in "unequivocal terms that she did not intend to appear at the hearing". Nevertheless, the hearing continued but it was instantly made clear that the allegations of misconduct related to one case only and in particular to "deadlines being missed". The Panel also appear to have taken into consideration the fact that the Registrant was "off sick" for a period of three months and that when she did return she had a new line manager. 
The letter from the Registrant was used as evidence and the Panel found that she had only "demonstrated limited acknowledgement of her failings" but they did accept that the Children and Family Court Advisory and Support Service (CAFCASS), the referring organisation, were experiencing "organisational changes". The outcome of 'caution' was reached because in conjunction with her poor health, her resignation and the fact that she was adamant that she did "not wish to return to work as a Social Worker...or maintain her registration with the HCPC", the Panel felt her misconduct in relation to one case did not warrant a "striking off order".

However, what is salient once more is that despite the Panel accepting that there were organisational issues at CAFCASS, the impact of which may have contributed to the Registrant's resignation, and the fact that her previous line manager, who had no issue with her practice before she went on sick leave, was also "off sick", is left unexplored. These issues appear to have played a significant role in her resignation, and, as a result, the profession has lost a social worker with "considerable experience". Prevailing organisational issues were, therefore, not only a frequent theme in the 'Struck Off' category but also within the 'Conditions of Practice/ Caution' categories. We even noted that in some cases the Panel found registrants' competence issues "understandable" because of problems emerging from the referring organisation.

In the case of ' $\mathrm{J}$ ' nine allegations of misconduct were filed by the local authority against the Registrant (who had been a team manager) which ranged from closing cases early, not responding to cases in a timely manner, allocating cases to a support worker instead of a social worker, fabricating case notes and other actions of dishonesty. Yet once the Panel heard evidence from the Registrant, they were also concerned with what they learned, 
accepting "the Registrant's uncontroverted evidence that there were staffing shortages in her locality" and that the allegations emerged, in part, because of "practices within the Council”. Because the Registrant appeared, in part, to take responsibility for addressing such organisational issues she was deemed to have demonstrated partial insight into her failings. Yet the problems that were agreed by Panel to have been present within that particular authority appear to have been discharged without proper investigation by the HCPC. Whilst we recognise that the HCPC openly claims this kind of issue is not within its remit, what this finding suggests is that these problems may still exist within that agency and thus may have been affecting other social workers at that time.

\section{Decision on Sanction: 'No Further Action'}

All the registrants who received an outcome of 'No Further Action' attended their hearing. The collective reason for why allegations against them were not proved appeared to be because they presented as 'credible' witnesses and were also able to provide evidence that there were serious organisational issues.

In the case of ' $\mathrm{K}$ ', the first hearing had to be adjourned because the Registrant produced "new" evidence in the form of her diaries. The minutes stated that:

The Panel considered whether to refuse to admit the proposed new evidence on the ground that its introduction was at such a late stage that it would be inappropriate to allow it to be adduced.

It is important to note that these diaries had not been seen by the Panel previously because the Council in question had not released them back to the Registrant until just before the hearing. It emerged that the information within these documents provided crucial information and demonstrated that the Council had not been entirely honest on a number of occasions. The majority of the allegations made against the Registrant were therefore 
found to be "not proved" and no further action against the Registrant was taken.

Surprisingly, despite the content of the diaries demonstrating the Registrant's innocence alongside the fact that the Council had not submitted this evidence, and thereby wasted the Panel's time and resources, the conduct of the Council does not appear to have been explored further.

Another interesting contrast in this category relates to the 'credibility' of the witnesses from the referring organisation. In previous categories, when registrants' credibility is questioned, their fitness to practise is challenged. Yet when a witness from the referring organisation is found to be "not credible" their fitness to practise is not considered impaired. This is especially apparent with the case of ' $L$ '. In this case, the Registrant's line manager made allegations that the Registrant showed poor time management and did not see service users regularly. However, the Registrant was able to disprove the allegation by demonstrating that he was facing "an impossible task" because his manager was often away from the office, front line staff were missing through long term illness, and there was "very high staff turnover and redeployment". The Registrant revealed that three of the twelve remaining social workers were left to manage the 156 cases that were allocated to the team and that he was often "on duty for up to a fortnight at a time". His way of managing the chaos was therefore to "prioritise patients over paperwork" which he said he would do again in the same circumstances. Yet while the Panel found that the witness was "credible, cogent" and "gave clear evidence", the manager's misleading referral or the appalling conditions under which he and others were working appear not to have been explored further. 


\section{Discussion}

Whilst we agree that social workers should demonstrate appropriate attitudes and adhere to professional standards in their practice (Banks, 2004; Kline and Preston-Shoot, 2012), our analysis of these cases has raised a number of important issues in terms of how this is measured by the HCPC within its regulatory framework. Firstly, it is concerning that when HCPC hearings take place decisions are made without the Registrant even being present. Whilst this is unavoidable in cases were the social worker has clearly disengaged from the process, in many cases life changing and condemning decisions are made about the Registrant without anyone on the Panel having ever met them or knowing for sure why they did not attend the hearing.

Secondly, we found that if Registrants were deemed wholly credible witnesses, they needed to attend their hearing and present to the Panel as a person who was completely remorseful for their actions; moderate repentance or slight insight into their failings rendered them merely partially credible witnesses. The outcome of the hearings appeared to, therefore, depend entirely upon whether the HCPC panel considered the registrant to be a 'credible', 'partially credible' or a 'non-credible' witness.

Although the HCPC (2013a), in its Fitness to Practice Report, does provide examples of what is considered as impaired practice, it does not provide an explanation of how different panels, hearing different cases, can provide equitable decisions on the severity of the complaints made. What is suggested from our findings is that the outcome of the hearing was not dependent on the perceived seriousness of a registrant's misconduct or competence, which leads to our third concern: the issue that professional capability issues are treated differently. This not only suggests that the HCPC process is 'not a level playing 
field' but also that the outcomes are highly subjective: they depend on the presentation of the registrant and the witnesses (Author, 2010:314). This is evident from the examples that we have presented in this paper, which support Wiles' (2011) concerns that defining and measuring suitable conduct for social workers is problematic because, in this context, we found that the 'seriousness' of the allegations often played an insignificant role in the Panel's considerations.

We acknowledge that it must be difficult for different panels to assess different cases in an equitable manner, irrespective of formal guidance, yet it is still concerning that this process is highly subjective. However, from the cases we analysed there is a distinct lack of consideration from the HCPC that this process, which is supposed to be 'accurate', has substantial limitations (HCPC, 2013a:1). We found that there are no explanations of how fairness is achieved, judgements made and equity established across the hearings of different cases. Outcomes appear to depend heavily on whether a registrant attends their hearing, and, if they do, how well they convince the Panel that they are sincerely apologetic for their actions. As Furness (2012) has pointed out previously, it needs to be recognised that social workers do make mistakes but displaying an insight into those errors so that the worker can improve on their practice does not need to take place through a formal investigation. This leads us to our final concern which relates to whether our regulator has actually replaced what should be an organisational procedure.

It is evident from our findings that the focus of the HCPC panel concentrates solely on the alleged misconduct of registrants. Yet in many of the cases when registrants have reported poor supervision, organisational issues and high caseloads, these problems do not appear to have been given sufficient weight by panel nor do they appear to have been pursued or 
remedied. This finding is particularly disconcerting, especially as the Munro Report (2012) highlighted that social workers need to be in a supportive and enabling environment if they are to be able to practise effectively.

\section{Conclusion}

Furness (2012) pointed out that because the HCPC only focuses on the actions and behaviour of the registrant, organisational failings are consistently overlooked. In addition, Meleyal (2011) has questioned whether the introduction of registration and regulation has led to organisations adopting a top down command with enforcement strategies to address issues that would have formerly been managed internally by employers. Rather than, therefore, the HCPC (2013: 8) properly exploring the 'balance of probabilities' that would entail weighing up both individual and organisational issues, the regulator appears to be more focused on deciding if the individual is accountable without considering the wider context of the situation.

The HCPC has always been clear that its remit does not include consideration of cases about organisations, its concern being only with individual professionals (HCPC, 2015a). Yet whilst there is an understandable differentiation in terms of initial complaints and concerns against individuals and organisations, we find it puzzling that when issues of organisational concern are raised and accepted within hearings, that such concerns are not referred to a relevant body able to hold the organisation to account. This is something that is alluded to in the Professional Standards Authority for Health and Social Care which has called for 'a more nuanced, more sophisticated use of professional and system regulation' which can ensure professionals are personally able to provide good care whilst being supported to do so within their workplace (PSA, 2015:13). This is important as our research suggests that the 
HCPC not only expects social workers to encounter and operate effectively within dysfunctional organisations but that they are aware of, and fail to pursue, the knowledge that there are other social workers in that agency who are likely to be working in similar unacceptable conditions.

As an organisation the HCPC holds a great deal of power over those professionals, in our case social workers, required to register with it. In detailing the process whereby registrants can be brought before its Fitness to Practise panel we have highlighted some areas that give concern as to how it operates and reaches its final decisions and subsequent sanctions. However, it has to be acknowledged that we have deliberately chosen practice cases and in this respect, we did not consider the more clear-cut cases where the HCPC plays a valuable role in protecting the public from criminal, abusive and/or incompetent workers. Nevertheless, the role of the HCPC in sanctioning those whose misdemeanours were, to a greater or lesser degree, affected by organisational failings and lack of resources runs the risk of individualising and scapegoating the social worker whilst neglecting systemic issues. Such a situation may also undermine public confidence in the profession and place service users at risk.

$\underline{\text { Notes }}$

No funding has been received for this study. 


\section{References}

Alston, M. \& Bowles, W. (2013) Research for Social Workers: an introduction to methods $3^{\text {rd }}$ edition, Abingdon: Routledge

Banks, S. (2004) Ethics, Accountability and the Social Professions, Basingstoke, Palgrave Macmillan.

Beddoe, E. (2010) Surveillance or Reflection: Professional Supervision in 'the Risk Society'. British Journal of Social Work 40 (4): 1279-1296

Braun, V. \& Clarke, V. (2006) Using thematic analysis in Psychology, Qualitative Research in Psychology, 3, 77-101

Carey, M. (2012) Qualitative Research Skills for Social Work. Farnham: Ashgate

Corbin, J.M. \& Strauss, A.L. (2008) Basics of Qualitative Research: Techniques and procedures for developing grounded theory: $3^{\text {rd }}$ edition. Thousand Oaks, California: Sage

Fox-Harding, L. (2008) Child social work, state and family in Kirkton, D. (Ed) Child Social Work Policy and Practice. London: Sage.

Furness, S. (2015) 'Conduct Matters: The regulation of social work in England', British Journal of Social Work, vol.45, pp.861-879.

Hakim, C. (1982) Secondary analysis in social research: a guide to data sources and methods with examples. London: Allen \& Unwin

Hakim, C. (1987) Research design: strategies and choices in the design of social research. London: Allen \& Unwin

Hammersley, M. (1990) Reading Ethnographic Research: A critical guide, London: Longmans Author (2011)

HCPC (2012a) 'What Happens if a concern is raised against me?', London: HCPC. http://www.hcpcuk.org/assets/documents/100008E2HPC_What_happens_if.pdf (accessed 13/11/15).

HCPC (2012b) 'Social Workers in England: Standards of Proficiency', London: HCPC.http://www.hcpc-uk.org/assets/documents/10003B08StandardsofproficiencySocialworkersinEngland.pdf (accessed 16/11/15)

HCPC (2012c) 'Practice Note: Finding that practice is 'impaired”, London: HCPC http://www.hcpc-

uk.org.uk/assets/documents/1000289FFindingthatFitnesstoPractiseis/mpaired.pdf (accessed 18/12/15) 
HCPC (2013a) 'Fitness to Practice Key Information Report'. London: HCPC http://www.hcpcuk.co.uk/assets/documents/10004E23Fitnesstopractisekeyinformation201 3.pdf (accessed 6/12/15)

HCPC (2013b) 'Practice Note: Interim Orders', London: HCPC http://www.hpcuk.org/assets/documents/10001ddbpractice note interim orders.pdf (accessed 18/1/16)

HCPC (2015a) 'Fitness to Practice Annual Report 2015' London: HCPC http://www.hcpcuk.co.uk/assets/documents/10004E22Fitnesstopractiseannualreport2015.pdf (accessed $6 / 12 / 15)$

Kirk, J. \& Miller, M. (1986) Reliability and validity in qualitative research, Qualitative Research Methods series, No 1, London: Sage

Kline, R. and Preston-Shoot, M. (2012) Professional Accountability in Social Care and Health, London, Sage/Learning Matters.

Author (2007)

Author (2010)

Meleyal, L. F. (2011) Reframing conduct: Acritical analysis of the statutory requirement for registration of the social work workforce, PhD thesis unpublished, University of Sussex, available online at http://sro.sussex.ac.uk/7665/.

Munro, E. (2012) The Munro Review of Child Protection: Final Report: A Child-Centred System, available online at www.education.gov.uk/publications/eOrdering Download/Munro-Review.pdf.

PSA (2015) (Professional Standards Authority) 'Rethinking Regulation', London: Professional Standards Authority for Health and Social Care, http://www.professionalstandards.org.uk/docs/default-source/psa-library/rethinkingregulation.pdf?sfvrsn=2 (accessed 5/1/15)

Rogowski, S. (2010) Social Work: The rise and fall of a profession, Bristol: The Policy Press. Robson, C. (1998) Real World Research: a resource for social scientists and practitioner researchers. Oxford: Blackwell.

Silverman, D (1999) Interpreting Qualitative Data: methods for analysing talk, text and interaction. London: Sage

Wiles, F. (2011) 'Blurring private-professional boundaries: Does it matter? Issues in researching social work students' perceptions about regulation', Ethics and Social Welfare, 5(1), pp. 36-51. 